\title{
THE FUTURE OF PHARMACIST CENTERED PATIENT CARE AT THE UNIVERSITY OF SOUTH FLORIDA IS HERE! ${ }^{1}$
}

\author{
What if we took pharmacy back to its DNA... back to its essence... and then we prescribed \\ empowerment, innovation, creativity, teamwork and personalization? --USF Health Website
}

Having pondered this question, which had been his guide and vision throughout his career, Dr. Kevin Sneed asked himself how technology could be used toward the next advancement of pharmacy related health care. As the Founding Dean of the University of South Florida College of Pharmacy (USF COP), Dr. Sneed was instrumental in hiring a team of pharmacists to join him in becoming catalysts for change in all levels of healthcare. Despite the wealth of knowledge his team at the USF COP had, he realized that they also required a review of many existing technologies, including those that improved collaboration with physicians, prevented drug interaction conflicts, reduced patient medication usage over time, and verified drug appropriateness through automated biometric data.

Dr. Sneed's passion was, in part, influenced by preventable patient care failures that pharmacists were exposed to. He was familiar with scenarios where patients were exposed to unnecessary medical conditions and reliance on medication that could have been avoided with the involvement of pharmacists in a team based clinical decision-making platform. Dr. Sneed argued that it was too prevalent that pharmacists were only known as prescription fillers. With the right processes in place, pharmacists could play a vital role in reducing drug interactions, providing education to both patients and other healthcare professionals about medications, as well as assisting with monitoring the efficacy of medications prescribed to patients.

Dr. Sneed and the COP team were part of the USF Health group, which was comprised of over 20 specialty centers, in areas like preventative medicine, primary care, skin care and physical therapy ("USF Health Morsani Center,” n.d.). The USF Health group had achieved a patient care breakthrough when it decided to invest in Epic, a software that allowed for its many divisions to record critical patient medical data. Due to the establishment of Pharmacy Plus, dubbed the "Pharmacy of the Future," Dr. Sneed indicated the time had come to modify Epic and/or expand USF Health COP into new technologies designed to address the issues of improved pharmacy centered patient care. Dr. Sneed knew he had to decide about how, could and should additional healthcare technology platforms be implemented within USF Health COP to further his guiding vision of improved health care.

\footnotetext{
${ }^{1}$ Copyright (C) 2018, Muma Case Review. This case was prepared for the purpose of class discussion, and not to illustrate the effective or ineffective handling of an administrative situation. Names and some information have been disguised. This case is published under a Creative Commons BY-NC license. Permission is granted to copy and distribute this case for non-commercial purposes, in both printed and electronic formats.
} 
BENJAMIN, CASTRO, LABARCA, UDOMVITTAYAKRAI, SALEEM

\section{USF Health}

The foundation of USF Health began in 1971 when the university's Medical School first opened its doors to students. Soon after, the College of Nursing opened in 1973, followed later by the College of Public Health in 1984. The newest member of the team, the College of Pharmacy (COP), accepted students in its inaugural class in 2011.

USF Health quickly developed into an enterprise for change in healthcare and an advocate for the quality of life for patients. With a network of specialists located across the Tampa Bay area, USF Health had successfully served a vast population of residents across Hillsborough County. Through a combination of talent and innovation, USF Health integrated research, education and healthcare, which culminated in a shared goal of making lives better.

This group's health care providers concentrated their efforts in various centers and institutions across the USF Tampa campus and Tampa Bay, which were strictly outpatient focused--thus patients received treatment without being admitted to a hospital. Inpatient care was provided through USF Health's partnership with Tampa General Hospital.

Under the umbrella and guidance of USF Health, Dr. Sneed's COP mission sought to revolutionize patient centered healthcare services, achieved through means of innovation, education, research and service (see Exhibit 1).

In spring 2015, USF Health, with Dr. Sneed's guidance, opened the "Pharmacy of the Future," conveniently located in the Morsani Center for Advanced Healthcare ("USF Health Pharmacy Plus,” n.d.) (see Exhibit 2). Dr. Sneed was excited about this accomplishment, for it fell in line with the strategic plans set for the college. USF Health Pharmacy Plus (Pharmacy Plus) created a personalized pharmacy experience for customers, broke away from the traditional behind-the-counter role of the pharmacists, and contributed to the development of the pharmacists as healthcare providers.

\section{The Development of Modern Day Pharmacy Practices}

The following quotes illustrate the major milestones in the development of modern day pharmacy practices in the United States.

The history of pharmacy in the United States was the story of a melting pot of new pharmaceutical ideas and innovations drawn from advancements that Europeans shared, Native American medicine and newly discovered medicinal plants in the New World. American pharmacy grew from this fertile mixture, and has impacted U.S. history, and the global course of pharmacy ("History of Pharmacy," 2017).

Major cities on the Eastern Seaboard followed Philadelphia's lead, establishing university training programs, professional associations and colleges of pharmacy that acted as professional associations like the PCP. New York City was among the quickest to follow suit with the New York College of Pharmacy, established 1829 ("History of Pharmacy," 2017).

The 19th century (1800s) birthed "pharmacy as we know it."...At the Second International Congress of Pharmacy in Paris, France, August 21 to 24, 1867, William Procter argued forcefully against the compulsory limitation of pharmacies (capping their number in a given city or province) under consideration, telling the assembled delegates that, in the U.S., there is not the slightest obstacle toward a multiplication of drug stores save that a lack of success and that the American public is a forceful agent of reform to keep unscrupulous operators in check. Procter's 
declaration was later seen as a defining statement of the American Way of Pharmacy ("History of Pharmacy,” 2017).

By 1900, most pharmacies stocked the shelves, partially or predominantly, with medicines prefabricated in masse by the growing pharmaceutical industry instead of custom-produced by individual pharmacist, and the traditional role of the scientifically trained pharmacist to produce medicines increasingly eroded. This shift worried many, raising concerns of quality control, professional irrelevance and more. William Procter lamented that, "If the pharmacist becomes a mere dispenser of medicines, he relapses into a simple shopkeeper" ("Pharmacies in the United States," 2016).

At the time of this case, there were approximately 67,000 pharmacies in the United States. Almost half were located within drug stores, grocery stores, department stores, medical clinics, universities, nursing homes, prisons and other facilities ("Pharmacies in the United States," 2016).

Procter's warnings eventually came true. Decades ago pharmacists were the "simple shopkeepers" limited to dispensing prefabricated drugs. Other professionals, and even patients, viewed pharmacists to be less important in comparison to other medical professionals, who were responsible for treating patients. Commonly employed in retail, pharmacists were only required to provide patients with consultation upon request. With hundreds of prescriptions filled within a day, customer interaction was very limited. This contributed to the stigma that Pharmacists were simple prescription fillers.

However, eventually the pendulum began to swing the other way, and pharmacists were once again being perceived by their traditional role as scientifically trained professionals endowed with knowledge of medicine to promote patient healthcare services. This change had rapidly developed in the 21st century, whereby the pharmacy trade became the art of selecting the best medication therapy for patients based on their history, physical assessment, co-morbid conditions, and socioeconomic factors. Pharmacists collaborated with the prescribing physician and other members of the medical team to provide the best treatment outcomes for patients. Their expertise included providing therapeutic options that were appropriate and adhered to national recommendations and guidelines.

\section{The Effects of the Pharmaceutical Industry and Information Technology on the Industry of Pharmacy}

Like the pharmacy industry, the modern day pharmaceutical industry had come a long way. The most common form of the pharmaceutical industry began in the United States during the period of 1818 to 1822. The availability of a few chemical manufacturers, constructed in Philadelphia, provided the avenue for the competitive industry to grow. This growing industry led to the start of The Food and Drug Administration (FDA). The FDA originated in 1902 by an act of Congress and regulated the modern pharmaceutical industry. Through extensive research and development, pharmaceutical firms could create and market legal drugs, vaccines, medical devices and biologics. These products, created for both humans and animals, were available by prescription and over the counter at pharmacies across the country.

During 2015, spending in the United States on prescription drugs rose 12 percent from the previous year to approximately $\$ 425$ billion before discounts (Cortez, 2016). Based on the results from "The 2017 Economic Report on US Pharmacies and Pharmacy Benefits Managers," big contenders in this market were CVS, Walgreens, Express Scripts and Walmart. These companies accounted for over 50 percent of 
the total prescription revenue in the country in 2016 (see Exhibit 3). The increase in sales had direct relations to technological advancements within healthcare.

Technological progress in this industry and in the broader healthcare sectors led experts to project the global pharmaceutical market sales to exceed $\$ 610$ billion in 2020. More than 50 percent of patients purchased drugs from visiting retail pharmacies, but technology led to a rise in internet drug purchasing activities. Prescription drug buyers considered nontraditional purchasing options more convenient and private relative to traveling to a physical pharmacy or drugstore. Some physicians also suggested internet pharmacies to some homebound patients to improve drug adherence (Cortez, 2016).

For many decades, information technology (IT) impacted the working lives of millions of people. With measurable benefits, many pharmacies like Pharmacy Plus welcomed the multiple avenues of using technology to automate daily activities and improve patient experiences. For prescribers and pharmacists, IT enabled the storage of structured patient records, facilitated the electronic prescribing, controlled the dispensing and administration of medicines, automated the handling of medicines in the supply chain and provided tools for monitoring the efficacy and safety of medicines in use. For the most part, these advances were initiated to increase revenues and profits. Regarding Health Information Technology's (HIT) impact on patient safety, it was mostly federal legislation that drove the adoption of said protocols.

In line with the transformation of the pharmacy industry, Dr. Sneed and USF Health were also dedicated to providing patients with the best quality medical care available with the help of IT. They prided themselves on researching the latest and safest therapies, treatments and technologies. With patient health as their highest priority, they diligently worked to transform and improve the practice of medicine by opening state-of-the-art centers and institutes. Across the USF Health group, new technologies were adopted to help providers contribute to the shared value of improving patient centered healthcare.

\section{The USF College of Pharmacy Business Model \& Use of HIT thus Far}

USF Health Pharmacy Plus operated using a business model like most retail pharmacies in the country. Drugs were purchased from wholesalers, usually at a cheaper rate, and then resold to patients. Drug prices varied, but the pharmacy aimed to recoup the purchase cost and dispensing fees through insurance payments, government reimbursements and patient out of the pocket payments. A purchasing agreement was established between USF Health and drug distributor, Cardinal Health, to provide the medications as needed for Pharmacy Plus operations. Like most retail pharmacies, Pharmacy Plus also generated revenue through over-the-counter sales and concession products.

Within the pharmacy, patients purchased common products, such as band aids, skin applicators, vitamins, heat patches, as well as other products developed by Tampa area companies. Important to their mission, the pharmacy sold various digital health devices to develop new ways to connect with their patients. These devices helped patients integrate digital apps and mobile technologies into their clinical care and daily health routine. Wearable devices were sold and could be prescribed to help patients better monitor and manage their health, take advantage of programs for acute or chronic illnesses, and monitor behavior changes and wellness habits. The following items were a few of the digital health devices sold at Pharmacy Plus (see Exhibit 4):

- Digital Blood Pressure Monitoring Devices

- Wireless Activity and Sleep Tracker 
- Wireless Body Analysis Scales

- Wearable Fitness Devices

The targeted population of USF Health Pharmacy Plus was USF Health patients, employees, students, and the Tampa Bay community who utilized retail pharmacy services. The pharmacy accepted most major insurance, including Medicare and Medicaid. Surrounded by popular retail chains, like Walgreens and Walmart, Pharmacy Plus offered personalized care that allowed them to create a niche in the market. Through Telehealth services, everyone that was involved in the care of the patients could communicate with each other, even remotely. The pharmacy also provided timely delivery services which made them stand out from the standard pharmacies.

With a large population of USF employees who utilized their services, Pharmacy Plus, equipped with a golf cart, would deliver medication to patients across the Tampa campus. Dr. Sneed embraced the idea of finding innovative ways of making Pharmacy Plus stand out from the rest of the other pharmacies, and not just in Tampa Bay. The newly established pharmacogenomic clinic was a major accomplishment and attracted new patients to Pharmacy Plus.

Pharmacogenomics used an individual's genetic information to help guide the selection of a medication or dose of a medication to optimize treatment response and minimize adverse drug events. The pharmacogenomics clinic at Pharmacy Plus helped individuals understand how their DNA influenced current and future treatments prescribed ("Pharmacogenomics Patient Information,” n.d.).

“The job of the pharmacist was never really to put a pill in a bottle. It is to provide healthcare,” stated Dr. Sneed, in his interview with WUSF (WUSF, 2014). With the aid of his advanced pharmacy, he attempted to make putting the pills in the bottle just a small part of the healthcare that people received and not the focus of what the pharmacist did. This was the principle behind Rex (see Exhibit 5).

Purchased from RxMedic, the robot called Rex was used to dispense drugs, label bottles, verify medication and seal medicine bottles. Rex streamlined the process of filling prescriptions and saved the pharmacists time, allowing them to interact and engage with customers.

Though Rex transformed the traditional pharmacy structure, the prescription referral process remained the same. USF Health doctors or nurse practitioners wrote the prescriptions, which was recorded into Epic, the electronic health record, and transferred immediately to the system at USF Health Pharmacy Plus. By the time the patient arrived at the pharmacy, medication was verified, and insurance coverage was confirmed. The automation of this system left time for pharmacist consultations. But this was not where Dr. Sneed wanted improved pharmacist care to end.

USF Health transitioned from Allscripts EMR to Epic in 2015 as the electronic healthcare record system. This shift strengthened the relationship between USF and its primary teaching hospital, Tampa General Hospital. Epic offered many other advantages over paper-based records:

- Eliminated time spent filling out paperwork

- Enabled quicker transmission of prescriptions 
- Provided greater convenience with a printed copy of your physician's "clinical note" to take home for reference

With access to Epic, pharmacists could refer to records of patient visits, including clinician notes and other vital information deemed beneficial to providing patients with the appropriate medicinal options. For patients with a chronic illness, the pharmacist was included in the care team, comprised of providers who discussed the best health and treatment plan for that patient.

\section{Technology Options}

Dr. Sneed had to decide how, could and should additional healthcare technology platforms be implemented within USF Health COP to further his guiding vision of improved health care.

Dr. Sneed strongly believed that team care was the best care for all patients, but saw a gap in how information was accessed, shared and used to determine the medication choices. Dr. Sneed reflected on patients who saw limited progress in their conditions or worsened medical conditions due to a failure to change medications. He remembered cases where medication was not the solution for a patient, but it was as simple as a lifestyle change. Dr. Sneed also worried about how adverse drug interactions of any sort could be reduced.

The following were the additional technology solutions the COP considered to address Dr. Sneed's concerns:

\section{Improved collaboration between pharmacists and physicians through Enterprise Social Networks}

Enterprise Social Networks (ESNs) provided platforms that allowed people to reach their internal audience in an open environment. This software was used in businesses to connect employees across the organization. Examples of ESNs that provided features that could improve the share of valuable information in a timely manner were Tibbr, Jive, Yammer and USF Communicator.

Could an ESN provide a constant open dialogue about a patient so that a pharmacist could have more information available to make better recommendations for the patient? In other industries, ESN's tore down the walls of internal communications. Employees could communicate across time zones and departments to share and interact naturally. ESN's also drove collaboration; employees could share and collaborate from anywhere, with anyone, on any device. It also allowed for horizontal (peer-to-peer) communications. Having broken down rigid hierarchies, ESN's gave employees a place to share companywide goals and encouraged open discussions. Given its success in other industries, theoretically an ESN could encourage physicians and pharmacists to share knowledge, information, and possible red flags to help the patients.

As experienced in other industries, however, poor employee engagement and risk of sharing patient's sensitive data could be areas of concern for the team. Given the busy schedules of care providers across USF Health, the COP would be challenged to get healthcare providers to engage in the social platform (Musso, 2016).

\section{Clinical Decision Support Software (CDSS) designed to prevent drug interaction conflicts}

Clinical Decision Support Software (CDSS) was designed to: (a) identify dangers/conflicts of drug on drug interactions (DDIs), (b) reduce the risk of medication errors, (c) reduce misdiagnoses, and (d) provide the entire care team with consistent and reliable information. A CDSS system could be beneficial 
for USF's COP since Epic's patient record software was not equipped with a pharmaceutical module, thus the alerts and flags provided by the CDSS system would be beneficial to the COP (Hitchcock, 2011).

There was one common drawback experienced by other organizations using a CDSS platform, which was the barrage of DDI alerts. The effect of the numerous alerts caused alert fatigue and a tendency to ignore all alerts. This drawback may be averted given that USF Health's COP supported outpatient services. Outpatients received fewer drugs, therefore the rate of alerts for an individual patient would be diminished (Horn \& Hansten, 2011).

\section{Reduce patient medication usage over time through Telepharmacy}

Telepharmacy was used to deliver pharmaceutical care via telecommunications to patients in locations where they may not have direct contact with a pharmacist. In theory, a pharmacy could use telepharmacy for video-conferencing, patient education and counseling purposes. The pharmacist could provide a personalized service to the patient that would include improved access to care, greater efficiency in treatment, reduced patient medication usage, and market positioning for the coming century (Angaran, 1999).

Telepharmacy was a great concept, however the challenge was putting it into practice. Staffing and coordinating work schedules for effective use of this platform was a challenge. The cost of implementing the necessary hardware, software, and operational costs was expensive for a young pharmacy. In addition, the COP would be challenged to review the laws and establish rules and procedures for telepharmacy operations since most pharmacies in the United States had not yet adapted to the concept of telepharmacies.

\section{Encourage patients to use wearable devices to better track and monitor their medical conditions (see Exhibit 6)}

Health monitoring devices were worn devices that aided consumers and healthcare providers in tracking health and fitness. These wearable devices had demonstrated an ability to provide an array of biometric information that was not limited to data gathered from medical visits.

These devices enabled pharmacists to obtain measurable biometric data gathered over a longer span of time, which, in theory, should have enhanced the verification of drug appropriateness. Wearable devices provided output and connected to the Web in various ways. Some enabled wearers to monitor their own readings using a mobile phone and a special website. Others allowed data to be downloaded and viewed by third parties such as healthcare managers or clinicians who were watching for disturbing trends that merit medical intervention. Wearable health monitoring devices had saved patient lives, from managing chronic disease to optimized fitness programs.

Pharmacy Plus provided an array of digital health devices that was available for sale to patients. With more insurance companies offering discounts and some covering digital health monitoring devices within health plans, this option became very popular.

Within Epic was MyChart. MyChart had the capability of being linked to mobile devices and wearable devices with the purpose of monitoring health conditions. With access to Epic, Dr. Sneed saw this as an opportunity to have more information about patients available, allowing for all providers to make better decisions about their health conditions. 
BENJAMIN, CASTRO, LABARCA, UDOMVITTAYAKRAI, SALEEM

Dr. Sneed was excited about the opportunity, but concerned with the challenges of patient engagement. The success of these health monitoring devices depended mostly on the patients. The patients would have to purchase the device, keep records of their biometric data and share that information with the pharmacist. Additionally, while these trackers and apps claimed to offer many health benefits to their users, lack of regulation made it difficult to provide patients with guaranteed results.

\section{Make no changes}

With a "working" system and very limited results to show that a change was necessary, Dr. Sneed was confronted with the option of leaving USF Health's current model unchanged. With the COP being so new to the team, it could be too early to decide if any changes were necessary. The idea of waiting for a better time crossed the mind of Dr. Sneed as he focused on other aspects within his role as Dean of the College of Pharmacy. He battled among many of his priorities and hoped to have a full staff of pharmacists who would have the expertise necessary to assist with these endeavors.

\section{Nuances of the Challenges}

Science and Technology in general had evolved in the 21st century at an exponential rate. In 2004, then President George W. Bush signed an executive order launching the Health Information Technology Adoption Initiative (“Transforming Health Care,” 2017). The area of Health Information Technology (HIT) had gone through a quantum leap in demonstrating improved benefits in patient care. However, the medical care industry appeared to be challenged in embracing HIT to its full potential.

Thus far, Federal Laws, designed to address these challenges, were responsible for each step of HIT progress adopted by the medical care industry. These laws provided financial incentives, legal protections and patient privacy rules compatible with HIT adoption. For example:

- The passage of the Patient Protection and Affordable Care Act (PPACA), required the use of electronic medical records for all healthcare practitioners (Little, 2015).

- The American Recovery and Reinvestment Act required all health care providers to demonstrate "meaningful use" of electronic medical records in order to continue their existing Medicaid and Medicare reimbursement levels ("Federal Mandates for Healthcare," n.d.).

It should be noted that a caveat to this conclusion existed, and that was where industry competition demanded embracing a technology portal, as was the case with telemedicine. Failure to pursue Telemedicine Technology resulted in an inability to compete and a loss of revenue that might financially cripple patient care facilities choosing not to evolve.

It was evident that, for the medical care industry to adopt further advances in existing HIT, the Federal Government had to continue with its direct intervention efforts. The mere effect of HIT's improving patient care was not enough to overcome the current implementation challenges being faced.

The U.S. Dept. of Health and Human Services acknowledged that studies identified a large number of barriers to the implementation of HIT. They stated that the barriers were classified as ("Barriers to HIT Implementation,” n.d.):

- " "situational barriers (including time and financial concerns)";

- "cognitive and or physical barriers (include insufficient computer skills)”; 
- "liability barriers (including confidentiality concerns)"; and

- "knowledge and attitudinal barriers."

Furthermore, the American Journal of Health-System Pharmacy summarized the problem of medical care facilities adoption of HIT's as follows (Siska \& Tribble, 2011):

Despite the theoretical and demonstrated benefits of HIT, the pace of adoption remains slow. The number of real and perceived barriers for HIT adoption has become virtually insurmountable. Without any significant regulatory or financial motivation, many hospitals and health systems have chosen to wait before crossing the HIT chasm.

This wait and see approach by medical care providers appeared to have trumped the urgency of improving patient care via HIT. Unlike the trucking industry, which saw an explosion of IT technologies with President Carter's deregulation initiatives, HIT technology advances appeared to be contingent upon increased regulation of the health care industry.

That dependency had proven to be a problem in its own right. For example, on Feb. 8, 2016, the Senate health committee unanimously passed bipartisan legislation that would have improved health information technology and was named "Improving Health Information Technology Act (S. 2511)." The United States Senate, Chairman Lamar Alexander (R-Tenn.) believed that this act's goal was to make electronic health records a means to assist patients. Senator Alexander stated (Pennic, 2016):

We have worked for months - with input from those who actually use the system - to help improve health information technology and I'm glad to see this legislation move forward as part of a successful first meeting on our committee's bipartisan biomedical innovation agenda.

The Improving Health Information Technology Act (S. 2511) would have (“Improving Health,” n.d.):

1. Implemented documentation reduction which permitted non-physician care team members to document in the physician's place. Encouraged HIT certification.

2. Established an unbiased rating system designed to help providers better choose HIT products. Shared HIT user feedback related to security, usability, and interoperability, among others.

3. Authorized the Dept. of Health and Human Services to establish information blocking practices deterrents regarding appropriate sharing of electronic health information.

4. Encouraged the use of patient-centered health record technology by means of certification which allowed patients to access their health information through secure and user-friendly software. Supported the use of Health Information Exchanges to promote patient access.

Though this bill was introduced by congress, it was never enacted (“Improving Health,” n.d.). This failure shed light on the most pressing challenge of all faced by HIT advancement (i.e., the difficulty in enacting ground-breaking legislation for further HIT adoption and breakthroughs).

Given the established uncertainty of new legislation enacted by congress, and executive order revocations by President Trump, the fact that the Affordable Care Act was a financially failed program, and that The 
Centers for Medicare \& Medicaid Services (CMS) rules governing "Meaningful Use" were administrative and thus subject to change and interpretation with each new U.S. Presidential Administration--Dr. Sneed was faced with a financial investment challenge for additional technology that may or may not be required or permitted. Dr. Sneed realized that playing it safe by meeting the current minimum HIT standards might be the prudent path should the aforementioned regulations collapse ending further HIT support.

\section{Insider's Insight}

Dr. Sneed was very familiar with other internal factors that could affect his ability to move forward. At USF Health, implementation of any new software or system that required access to the information or USF systems, secured behind USF firewall, required thorough review by the USF Health IT. Depending on the complexity of the system/software, the review and discussion process could take years to come to fruition. Dr. Sneed had to seek out the option that did not impose a very high risk on the institution.

Additionally, financing any option was a concern. USF College of Medicine was in the process of investing in a new home in the downtown Tampa, Channelside district (Senecal, 2017). Dr. Sneed was integral in the discussions about moving downtown. He had planned to find funding to secure a floor in this new building. Close to the university's state-of-the-art simulation center, this was an excellent opportunity to improve the educational experience for the college's future pharmacists. Dr. Sneed had to decide which plan would not be too expensive, benefited the patients directly, and resulted in some return on investment for the college.

\section{Summary}

Decisions about improving patient healthcare using technology was a topic of discussion on a national platform for decades (see Exhibit 7). As the newest professionals to join the USF Health team, Dr. Sneed envisioned how his team of pharmacists could be an integral part of USF Health's mission to improve patient healthcare. Filled with innovative ideas, he was determined to be successful. He knew that any decision made towards improving patient healthcare would improve the reputation of USF Health and, most importantly, would result in a healthier community of people.

For many years, the role of the pharmacist was viewed as less important in comparison to other medical professions. Dr. Sneed saw that the societal idea of a pharmacist being just a prescription filler adversely affected the patient healthcare. Within USF Health, he valued the team care approach, but saw the gap in how information was recorded and shared to improve patient's health conditions.

However, Dr. Sneed understood the difficulties and uncertainties surrounding the protocols he wanted to implement at USF Health. Issues regarding patient privacy and security made him very concerned about what were the best options. Should he sit and wait for more information as he observed the growth and developments at USF Health? Would the physicians support the attempt to make patient care more pharmacist centered (see Exhibit 8)? Was this what patients cared about (see Exhibit 9)? Would his innovations provide significant improvement in patient health outcomes?

\section{References}

Angaran, D. (1999, July 01). Telemedicine and telepharmacy: Current status and future implications. Retrieved April 24, 2017, from http://www.ajhp.org/content/56/14/1405.short

Barriers to HIT implementation. (n.d.). Retrieved April 24, 2017, from https://healthit.ahrq.gov/health-ittools-and-resources/health-it-costs-and-benefits-database/barriers-hit-implementation 
Cortez, M. (2016, April 14). Prescription drug spending hits record $\$ 425$ billion in U.S. Retrieved April 24, 2017, from https://www.bloomberg.com/news/articles/2016-04-14/prescription-drugspending-hits-record-425-billion-in-u-s

Federal mandates for healthcare: Digital record-keeping requirements for public and private healthcare providers. (n.d.). Retrieved April 24, 2017, from https://www.usfhealthonline.com/resources/healthcare/electronic-medical-records-mandate/

History of pharmacy in the United States. (2017, April 03). In Wikipedia. Retrieved April 24, 2017, from https://en.wikipedia.org/wiki/History_of_pharmacy_in_the_United_States

Hitchcock, R., MD. (2011, November 28). Top 5 benefits of clinical decision support in the ED. Retrieved April 24, 2017, from http://www.healthcareitnews.com/blog/top-5-benefits-clinicaldecision-support-ed

Horn, J., PharmD FCCP, \& Hansten, P., PharmD. (2011, August 10). Customization of drug interaction software: Caution is warranted. Retrieved April 24, 2017, from http://www.pharmacytimes.com/publications/issue/2011/august2011/customization-of-druginteraction-software

Improving health information technology act (2016 - S. 2511). (n.d.). Retrieved April 24, 2017, from https://www.govtrack.us/congress/bills/114/s2511

Little, K. S. (2015, May 18). The electronic medical records (EMR) mandate. Retrieved April 24, 2017, from https://www.healthcarelaw-blog.com/2013/01/the-electronic-medical-records-emr$\underline{\text { mandate.html }}$

Musso, A. (2016, March 03). Why internal communicators need enterprise social networks. Retrieved April 24, 2017, from http://bananatag.com/hub/internal-comms/why-internal-communicatiorsneed-enterprise-social-networks/

Pennic, J. (2016, February 09). Senate health committee passes bill to improve health it. Retrieved April 24, 2017, from http://hitconsultant.net/2016/02/09/senate-health-committee-passes-legislation-toimprove-health-it-for-patients-doctors-hospitals/

Pharmacies in the United States. (2016, December 20). In Wikipedia. Retrieved April 24, 2017, from https://en.wikipedia.org/wiki/Pharmacies_in_the_United_States

Pharmacogenomics patient information. (n.d.). Retrieved April 25, 2017, from http://health.usf.edu/pharmacy-plus/patients

Senecal, A. (2017, February 09). USF unveils preliminary renderings for new medical school and cardiovascular institute in downtown Tampa. Retrieved May 03, 2017, from http://hscweb3.hsc.usf.edu/blog/2017/01/31/usf-unveils-preliminary-renderings-new-medicalschool-cardiovascular-institute-downtowntampa/?utm source=usfhealth home\&utm medium=imagelink\&utm content=small image\&utm campaign=health home 
Siska, M. H., \& Tribble, D. A. (2011, June 15). Opportunities and challenges related to technology in supporting optimal pharmacy practice models in hospitals and health systems. Retrieved April 24, 2017, from http://www.ajhp.org/content/68/12/1116.short

Transforming Health Care: The President's Health Information Technology Plan. (n.d.). Retrieved April 24, 2017, from https://georgewbushwhitehouse.archives.gov/infocus/technology/economic_policy200404/chap3.html

USF health morsani center for advanced healthcare. (n.d.). Retrieved April 08, 2017, from http://health.usf.edu/doctors/locations.htm

USF health pharmacy plus. (n.d.). Retrieved April 03, 2017, from http://health.usf.edu/pharmacy-plus/

WUSF. (2014, September 30). Check out hi-tech highlights of USF health pharmacy plus. Retrieved April 25, 2017, from https://www.youtube.com/watch?v=k9g6HwFcD_8

\section{Acknowledgements}

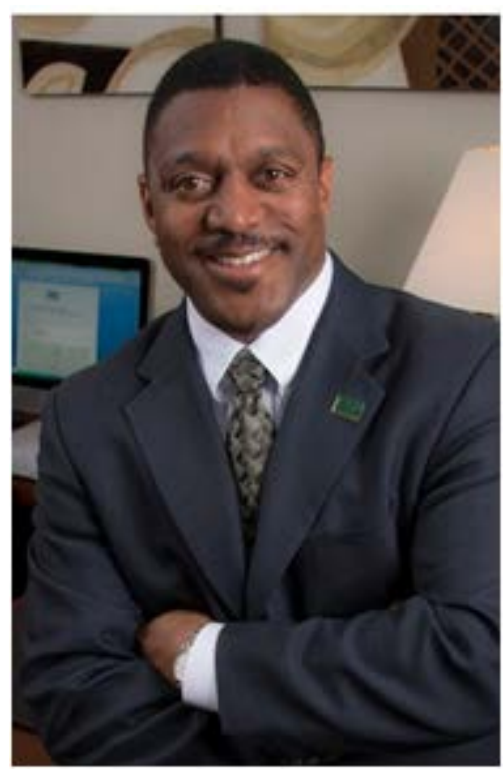

This case study was possible with the effort and support of Kevin Sneed, PharmD, Senior Associate Vice President, USF Health \& Dean, College of Pharmacy.

Dr. Sneed is a tenured Professor and the founding Dean of the USF College of Pharmacy. He also serves as a Senior Associate VicePresident for USF Health. His educational background includes a Bachelor of Science Degree in Biology with a concentration in Microbiology from the University of Central Florida. Dr. Sneed received his Doctor of Pharmacy Degree from Xavier University of Louisiana College of Pharmacy, where he received numerous clinical and leadership awards. He completed an Ambulatory Care Pharmacy Practice Specialty Residency at Bay Pines Veteran's Administration Medical Center.

Dr. Sneed is very engaged in emerging health technologies, and created USF Health Pharmacy Plus, which he touts as "The Pharmacy of the Future!” He has published numerous articles in peer-reviewed journals, book chapters, abstracts, poster presentations, and has participated in multiple grant projects and clinical trials.

Dr. Sneed serves on the board of directors and advisory committees for several organizations, including Area Health Education Center (AHEC) - University of South Florida, USF Nanomedicine Research Center (UNRC), and Hillsborough County Sickle Cell Association. He participates in many community endeavors on an annual basis, most notably the Florida Cancer Education Network Men's Health Forum in Tampa, FL. He is very active in national and state organizations, among which include NPHA, ASHP, AACP, FPA, FSHP, and Kappa Alpha Psi Fraternity, Inc.

Source: Welcome to USF Health at the University of South Florida, Tampa. (n.d.). Retrieved May 03, 2017, from http://health.usf.edu/VP/leadership/sneed.htm 


\section{Biographies}
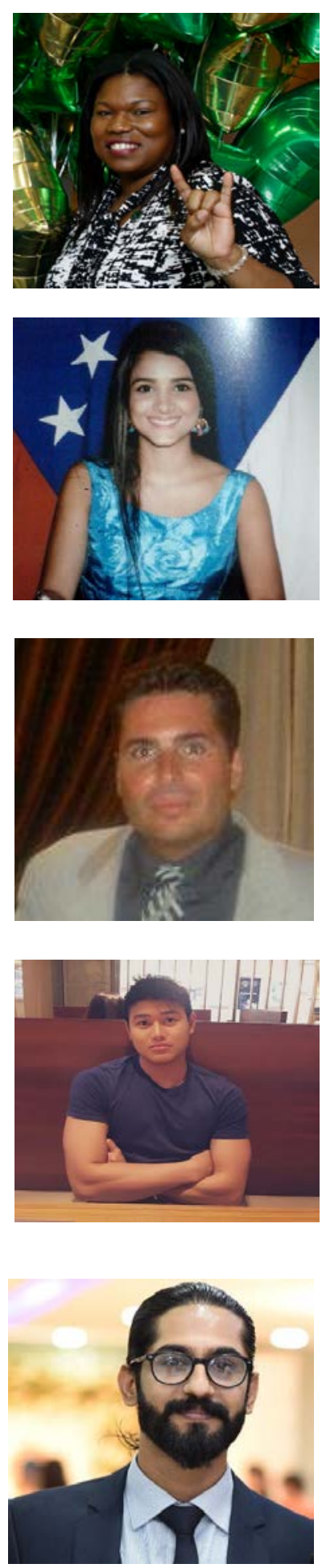

Danisha Benjamin is a native of the U.S. Virgin Islands residing in Tampa, FL. She earned a Bachelor of Arts degree in Accounting from the University of the Virgin Islands in 2010. Danisha works for the University of South Florida College of Pharmacy and is currently pursuing a Graduate Certificate in Business Foundations from USF, with interest in attaining a Master of Business Administration, with a specialization in Healthcare Management.

Gabriela Castro graduated from the Universidad Católica Andrés Bello located in Venezuela in 2014 with two bachelor's degrees; the first one in Business Administration and the later in Accounting. For the past four years, Gabriela has worked in Pricewaterhouse Coopers Venezuela as an audit and assurance apprentice, Eagleburgmann Venezuela as a financial analyst, and Citigroup Tampa as an Anti-Money Laundering Analyst. Currently, Gabriela is pursuing a Graduate Certificate in Business Foundations through USF, before applying to the Master of Business Administration program.

Joseph "Jude" LaBarca, J.D., a St. Petersburg, FL resident is also a telecommute C.E.O. for a Brooklyn, N.Y. based company (www.piloarts.com). He is also a member of the N.Y. \& FL Bar. While working at a law firm based in Rome, Italy, he co-authored the publication "Doing Business In Italy." As business is his passion, Jude is pursuing his M.B.A. at USF and has been inducted into the honor society (Phi Kappa Phi) for being in the top 10\% of his class. He welcomes all LinkedIn connections at: https://www.linkedin.com/in/judelabarca/

Somsak Udomvittayakrai completed a Bachelor’s Degree in Business Administration majoring in International Business Management from Assumption University in Thailand in 2015. Somsak has worked for the real estate company Walailak Co. in Bangkok as well as working with executives of another company selling construction equipment in Bangkok. Currently, Somsak is pursuing a Master's Degree in Science of Business Management at the University of South Florida.

Ahmed Saleem is a Master of Science in Management student at the University of South Florida. He earned his Bachelor's in Business Administration from International Islamic University Islamabad (IIUI), with a concentration in Marketing from Pakistan. Before starting his academic career at USF, Ahmed managed a variety of departments and supervised employees at his full-time job for five years. He worked as an assistant manager and manager for different textile companies in Pakistan. 


\section{Exhibit 1: College of Pharmacy: Mission, Value and Values}

\section{Mission:}

USF College of Pharmacy's Mission is to REVOLUTIONIZE HEALTH by:

- Innovation of patient centered healthcare through education, research, and service

- Empowerment of students, professionals, and patients as catalysts for change at all levels of health

\section{Vision:}

By 2018, USF College of Pharmacy will achieve interprofessional excellence in:

- Geriatrics

- Personalized Medicine

- Informatics

- Leadership

Values:

- Innovation

- Leadership

- Diversity

- Interprofessional collaboration

- Interdisciplinary research

- Evidence-based applications

- Teamwork

- $\quad$ Life-long learning

Source: College of Pharmacy. (n.d.). Retrieved May 01, 2017, from http://health.usf.edu/pharmacy/mission_vision 


\section{Exhibit 2: USF Health Pharmacy Plus}
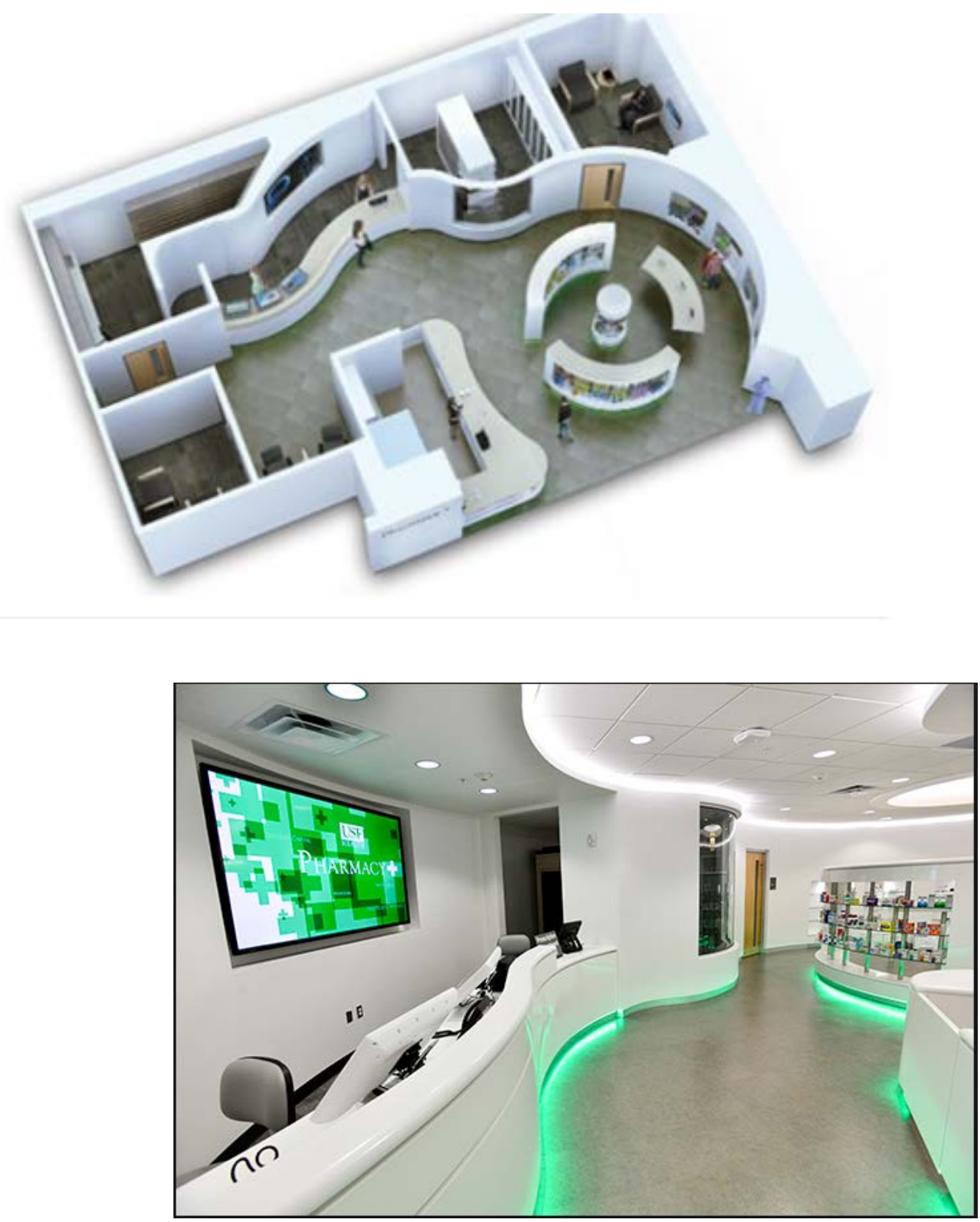

Source: USF health pharmacy plus. (n.d.). Retrieved April 03, 2017, from http://health.usf.edu/pharmacyplus/ 


\section{Exhibit 3: Retail Pharmacy Competitors}

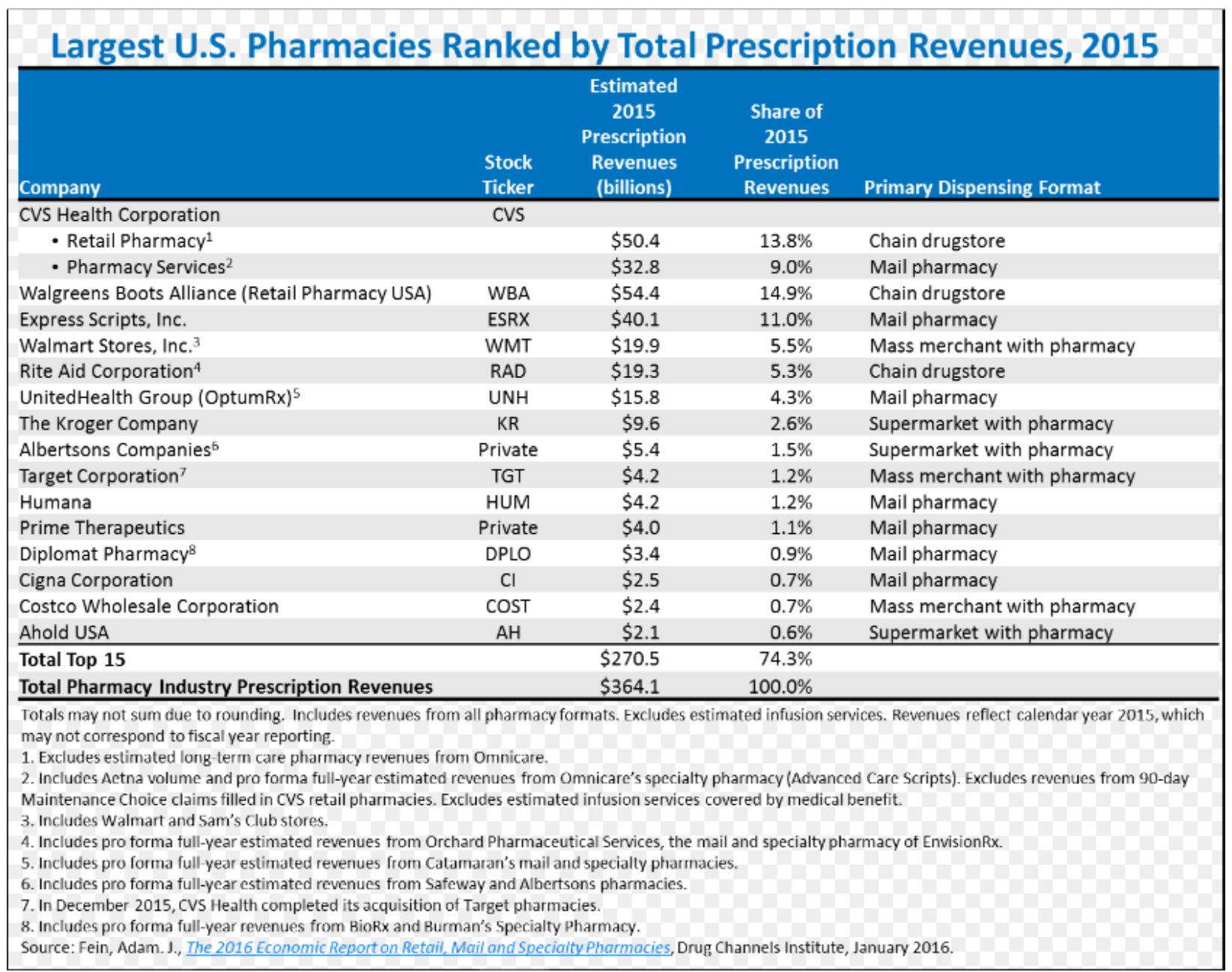

Source: Fein, P. A. (2016, January 28). The top 15 pharmacies of 2015. Retrieved April 24, 2017, from http://www.drugchannels.net/2016/01/the-top-15-pharmacies-of-2015.html 
Exhibit 4: Examples of iHealth Devices

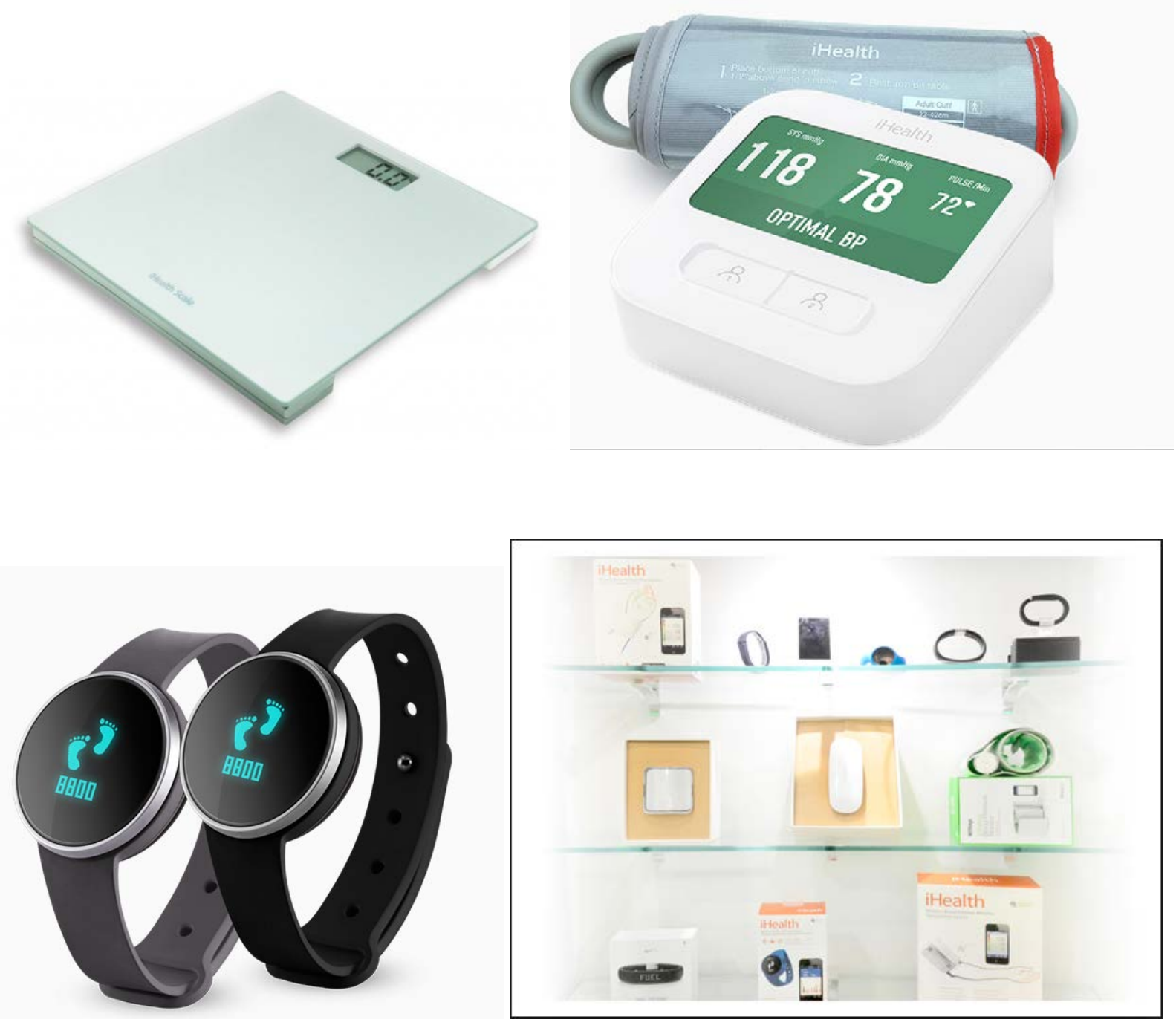

Source: https://ihealthlabs.com/ 


\section{Exhibit 5: Rex: Automated Drug Dispensing System}

\section{Pharmacy Automation: RxMedic ADSTM}

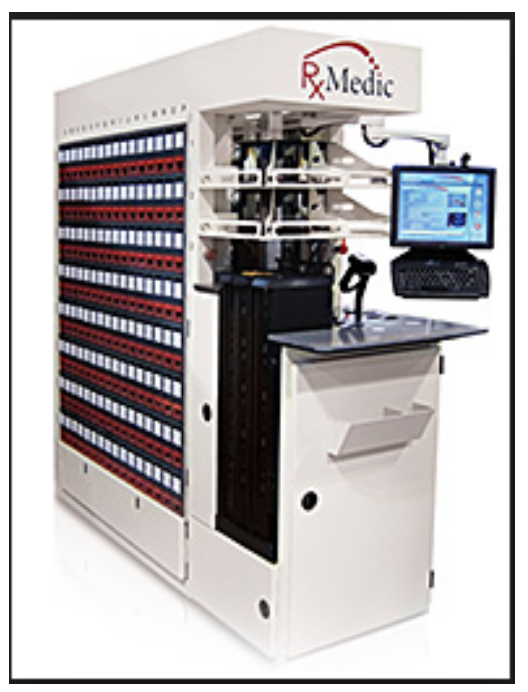

\section{Robotic Dispensing System}

The RxMedic Automated Dispensing System (ADS) automates up to 256 of a pharmacy's highest volume drugs. Unique patient safety features, combined with robotic speed and accuracy, make this pharmacy robot a great addition to retail pharmacies, employee pharmacies, hospital outpatient pharmacies and mail-order facilities.

\section{Capacity of RxMedic ADS}

The RxMedic ADS has incredible capacity: up to 256 standard cells, or 128 super cells can be combined in a combination to best suit the unique needs of any pharmacy. It can handle high volume easily, automating even the most difficult to count oral solids. ADS pharmacy automation fills up to $800 \mathrm{f}$ prescription volume per day, reducing the time spent preparing orders and increasing the time available for customer service and for revenue generating projects.

\section{Pharmacy Technology Eliminates Cross Contamination}

Each ADS cell counts and dispenses drugs directly into the vial, eliminating the risk of cross contamination. ADS does not use compressed air, but a unique vacuum technology and HEPA filtration to provide unprecedented air quality.

\section{Patient Safety and Prescription Accuracy}

RxMedic offers a unique patient safety feature on its automated dispensing and counting products. ADS takes a digital image of every filled prescription and stores it for future reference. Photo verification of vial contents enhances patient safety and provides documentation for quality assurance.

\section{ADS: Easy, Flexible Operation}

ADS has removable, auto-calibrating cells, making it easy for a pharmacy to change out drugs on-site in minutes. It interfaces with any pharmacy management system, offering a bi-directional integration advantage with QS/1. The collation area holds up to 200 capped and labeled vials; pharmacies with IVR can fill prescriptions robotically after-hours.

Source: ADS - RxMedic pharmacy automation. (n.d.). Retrieved May 01, 2017, from https://www.rxmedic.com/products/pharmacy-robotics/automated-dispensing-system.html 


\section{Exhibit 6: Digital Health Tracking through Mobile Device/Apps}
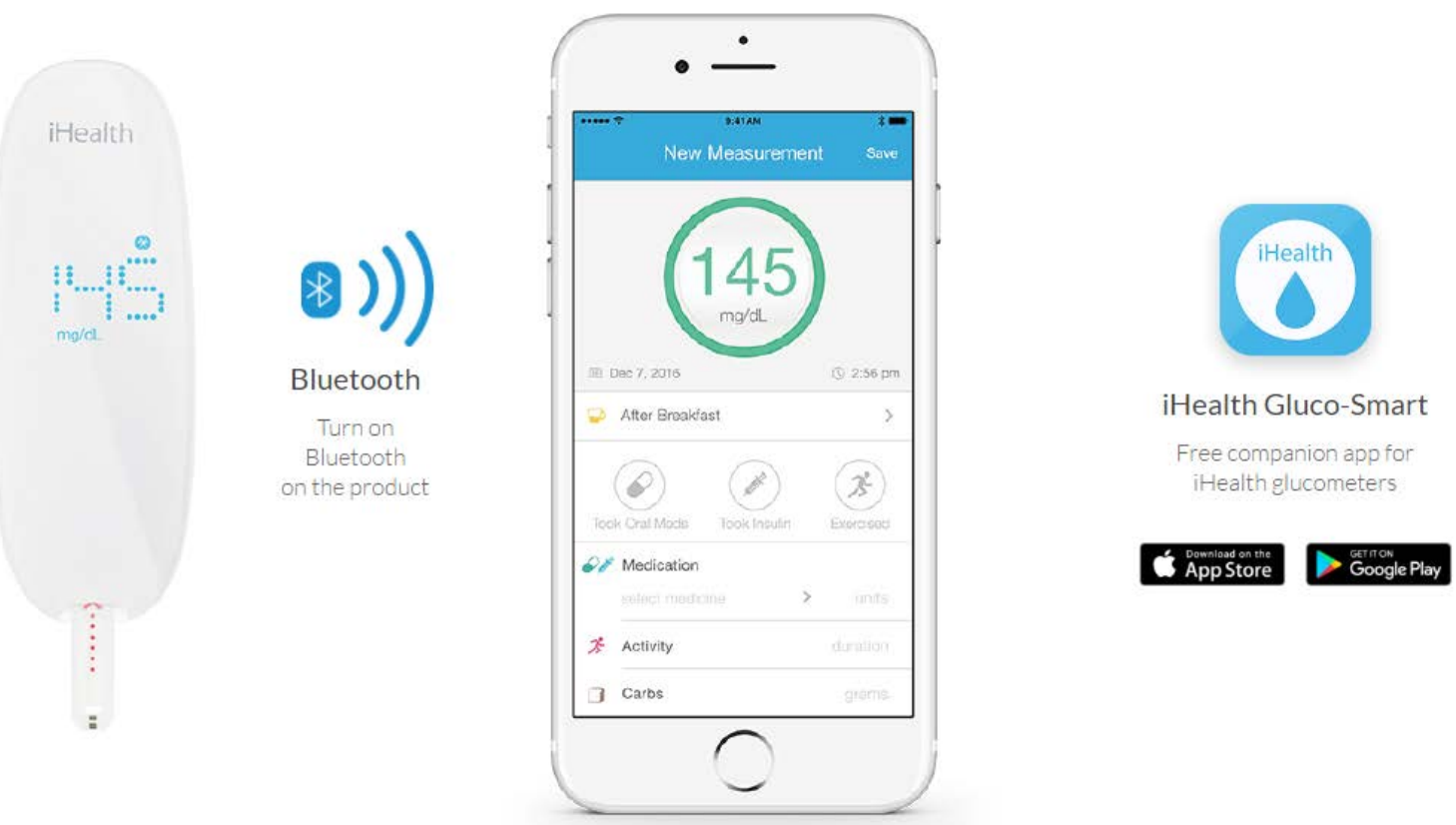

Source: USF health pharmacy plus. (n.d.). Retrieved April 03, 2017, from http://health.usf.edu/pharmacyplus/ 


\section{Exhibit 7: Technologies with Great Potential to be Implemented in the US Health Industry over the next Decade}

Figure 6: Eight technologies with great potential to disrupt the US health industry over the next decade

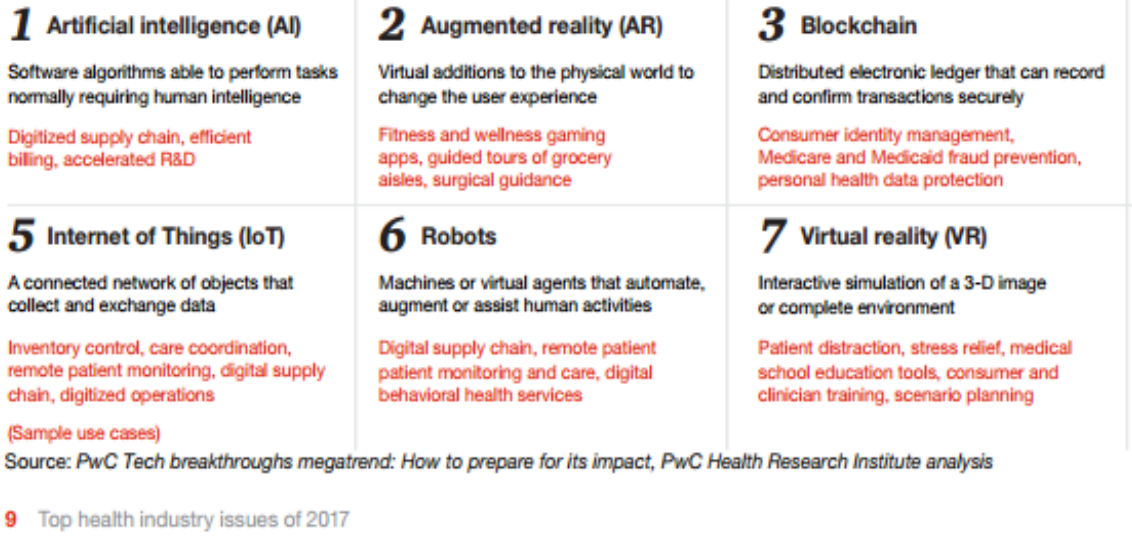

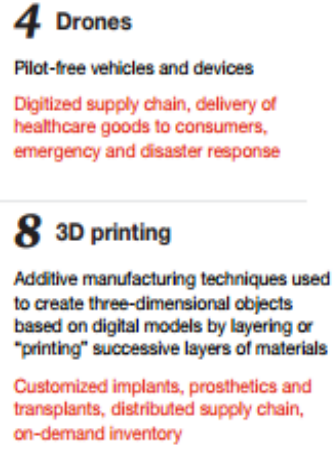

\section{3D printing}

Additive manufacturing techniques used to create three-dimensional objects based on digital models by layering or Customized implants, prosthetics and transplants, distributed supply chain, on-demand inventory

Source: Top health industry issues of 2017: A year of uncertainty and opportunity. Money matters: Billing and payment for a new health economy. (n.d.). Retrieved May 03, 2017, from https://www.pwc.com/us/en/health-industries/top-health-industry-issues/assets/pwc-hri-top-healthcareissues-2017-chartpack.pdf 


\section{Exhibit 8: How Physicians Distribute their Time across Various} Activities

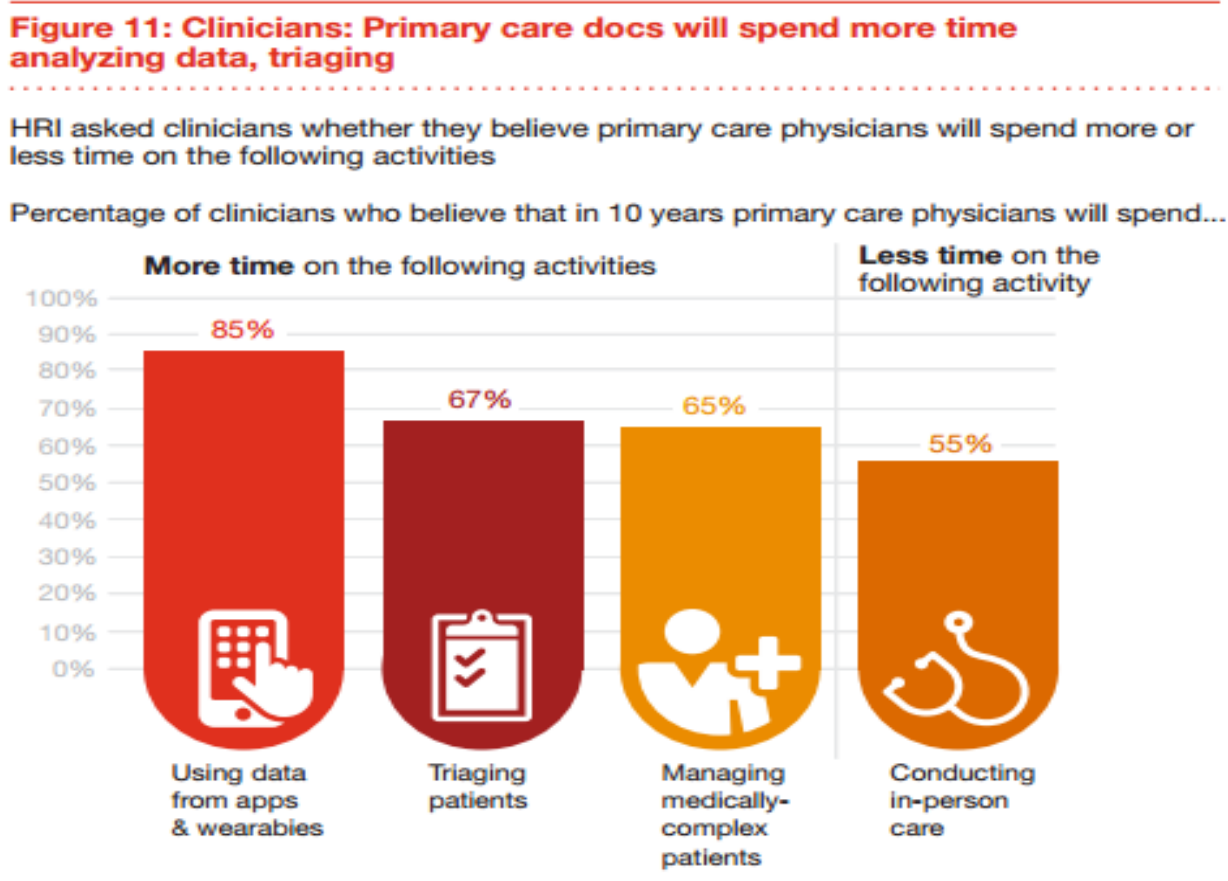

Source: PwC Health Fesearch Institute Workforce Survey, 2015

Source: Top health industry issues of 2017: A year of uncertainty and opportunity. Money matters: Billing and payment for a new health economy. (n.d.). Retrieved May 03, 2017, from https://www.pwc.com/us/en/health-industries/top-health-industry-issues/assets/pwc-hri-top-healthcareissues-2017-chartpack.pdf 


\title{
Exhibit 9: Patients Want more Nutrition Advice from these Healthcare Resources
}

\begin{abstract}
Figure 8: Consumers want more nutritional advice, especially from their healthcare resources

Consumers were asked whether they would take advantage of free advice for weight management or help with diet-related medical conditions from a nutritionist or dietitian from each of these entities. Percentage of respondents answering yes:
\end{abstract}

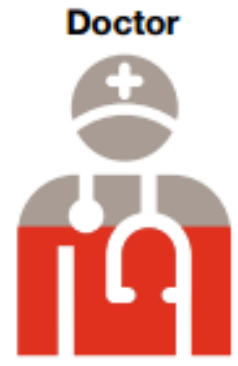

$79 \%$

\section{Employer}

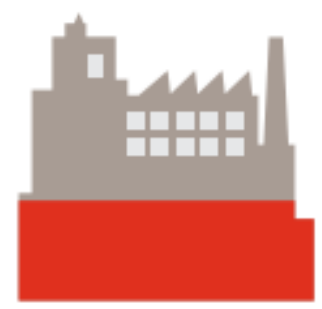

$38 \%$
Pharmacy

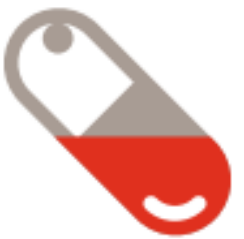

$59 \%$
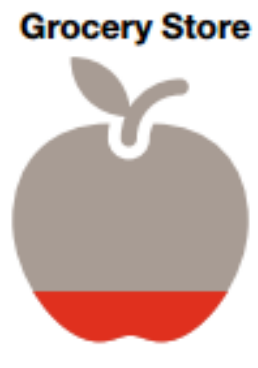

$28 \%$
Gym

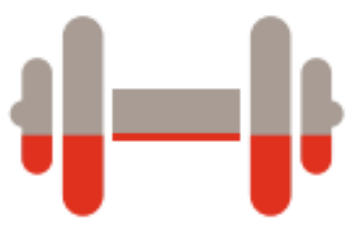

$41 \%$
Big Box Store

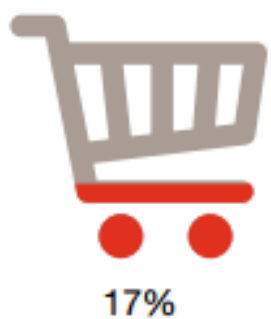

Source: PwC Health Research Institute Consumer Survey, 2016

Source: Top health industry issues of 2017: A year of uncertainty and opportunity. Money matters: Billing and payment for a new health economy. (n.d.). Retrieved May 03, 2017, from https://www.pwc.com/us/en/health-industries/top-health-industry-issues/assets/pwc-hri-top-healthcareissues-2017-chartpack.pdf 